\title{
Changes in Phytochemicals and Determination of Optimum Fermentation Time during Black Tea Manufacturing
}

\author{
M. M. Rahman*, M. M. Hossain, R. Das, I. Ahmad \\ Department of Food Engineering and Tea Technology, Shahjalal University of Science and \\ Technology, Sylhet- 3114, Bangladesh
}

Received 11 February 2020, accepted in final revised form 3 July 2020

\begin{abstract}
Black tea processing consists of four steps, namely withering, CTC, fermentation and drying, while cup quality made tea mostly controlled by fermentation step. This study evaluated biochemical changes at different stages of black tea processing in Bangladesh and determined the optimum fermentation time. Samples were collected from different tea processing stages to measure major phytochemicals and time intervals during fermentation to measure theaflavins and thearubigins ratio. Caffeine content was the least susceptible to processing steps. Biochemical changes started at withering, cell maceration and enzymatic oxidation started at CTC processing, thus the major reduction in the reducing sugar (20.46 to $04.95 \mathrm{ppm}$ ), catechin (16.88 to $7.95 \mathrm{ppm}$ ) and polyphenol (42.30 to $30.73 \mathrm{ppm}$ ) occurred here. The significant changes appeared during fermentation when polyphenol content decreased from 44.66 to 18.23 and catechin from 17.41 to $03.98 \mathrm{ppm}$ due to the breakdown of these compounds to theaflavins (TF) and thearubigins (TR). The TF and TR ratio increased with fermentation time, and the highest of 1:8.4 was found at $50 \mathrm{~min}$, which turned into 1:10 in the final product. The made tea quality parameters were comparable or better at fermentation time of $50 \mathrm{~min}$ than the quality of the black tea available in market.
\end{abstract}

Keywords: Tea processing; Fermentation or oxidation; Theaflavins and thearubigins; Fermentation time.

(C) 2020 JSR Publications. ISSN: 2070-0237 (Print); 2070-0245 (Online). All rights reserved. doi: http://dx.doi.org/10.3329/jsr.v12i4.45452 J. Sci. Res. 12 (4), 657-664 (2020)

\section{Introduction}

Tea (Cameliasinensis (L.) O. Kuntze) is one of the most popular non-alcoholic beverages worldwide, and its popularity is increasing rapidly. Bangladesh is the 9th tea producing country and contributing approximately $2 \%$ of world production. While tea production is steadily growing in Bangladesh, the export is steadily decreasing. One of the primary reasons is the quality deterioration besides many other factors like an increase in domestic consumption [1].

Tea processing consists of a series of stages starting from the harvesting of fresh tea leaves (crop shoots comprising three leaves and a bud (>75\%)) called plucking, through intermediate processing called withering, CTC (Crush, Tear and Curled), fermentation, at

${ }^{*}$ Corresponding author: mahfuz27_sust@yahoo.com 
last to dry for manufacturing black tea [2-4]. Withering reduces the moisture content of tea leaf to make leathery and soft, CTC chops into small and uniform pieces to make granular leaf particles. Among these stages, fermentation (oxidation) is considered as the most important step as the quality of tea greatly depends on this stage. Most of the important biochemical changes occur during the fermentation stage, mainly the oxidation of polyphenol and catechin by the polyphenol oxidase and peroxidase enzyme to form oxidized polyphenolic compounds such as theaflavins (TFs) and thearubigins (TRs) $[3,5,6]$. The oxidization of catechins forms orthoquinones, which then condensed to form theaflavins (TFs). In addition, oxidation of gallic acid occurs in order to form epitheaflavic acids which condensed with TFs to produce the thearubigins (TRs) [5]. TFs, TRs, and HPS are the most influential bioactive compounds of black tea quality. TFs content determines the briskness, brightness, and quality of the liquor of tea [7]. At the same time, TRs are responsible for color, body and taste, and an optimum fermentation produces a proper balance of TFs and TRs [3,5,7]. For the good quality of black tea, the TF and TR ratio must be maintained from 1:10 to 1:12 [3,5].

Although fermentation is one of the critical operations, usually it is taken place on the floor, trough or conveyor with a leaf thickness of $10-15 \mathrm{~cm}$ at room temperature $[3,8]$. Considering all of the environmental factors are constant, the optimum residence time of the fermentation plays a pivotal role in the TF and TR ratio that decide the final quality of the finished black tea. On the other hand, presence of catechins (flavonols) and caffeine in tea leaves also play an important role in determining the quality of black tea [9]. Optimum residence time or fermentation time is such important that research is going on to manufacture electronic noses to determine optimum fermentation by detecting flavor $[4,8]$. However, during black tea processing in Bangladesh, optimum fermentation is determined by the visual observation of color when changed to brown from green according to the method of Ullah [10]. This process does not have a definite time usually varies from $30 \mathrm{~min}$ to $90 \mathrm{~min} \mathrm{[10].} \mathrm{Therefore,} \mathrm{this} \mathrm{research} \mathrm{aimed} \mathrm{to} \mathrm{determine} \mathrm{an}$ optimum fermentation time that would save manufacturing costs and also help to produce a better quality of tea. The objectives of this study were; (1) to measure the proximate and phytochemicals change to occur at different stages during tea processing and (2) to determine the optimum fermentation time by analyzing the TF: TR and different quality parameters.

\section{Materials and Methods}

\subsection{Sample collection}

Samples were collected from a tea factory of Sylhet, Bangladesh during the period of July -October 2015. The samples, namely fresh leaves, withered leaves, CTC rolled leaves, fermented leaves, and dried leaves or made tea, were taken at five different stages of the tea manufacturing process. The chemical analyses were started immediately after collection in the FET laboratory of Food Engineering and Tea Technology department, 
Shahjalal University of Science and Technology, Sylhet, Bangladesh. All the chemicals and reagents were used in the experiments were analytical grade.

\subsection{Proximate and phytochemicals analysis}

After collecting the sample, moisture and lipid content were measured [11,12]. Then one gram sample was ground and mixed with $100 \%$ ethyl alcohol, followed by filtered to take out $50 \mathrm{~mL}$ of ethyl alcohol extract. This alcoholic extract was used for subsequent analysis.

Reducing sugar (dextrose equivalents) was extracted with alcohol. Ice cold acidified anthrone reagent $(0.2 \%, \mathrm{w} / \mathrm{v})$ was added in the time of boiling for $8 \mathrm{~min}$, and absorbance was taken at $630 \mathrm{~nm}$ [13]. The total polyphenols content was determined by FolinCiocalteu's reagent method [14]. Chlorophyll a, b, and carotenoids were measured at the wavelength of 470,653, and $666 \mathrm{~nm}$, respectively, using UV-Visible spectrophotometer [15]. To determine the Catechin content, $2 \mathrm{~mL}$ alcoholic extract of the sample was added to $6.5 \mathrm{~mL}$ of ice-cold vanilla (1\% vanillin in $70 \%$ sulfuric acid), and absorbance was measured at $510 \mathrm{~nm}$. In addition, caffeine was extracted with chloroform after boiling $5 \mathrm{~g}$ sample with $30 \mathrm{~mL}$ water and $2 \mathrm{~g}$ sodium carbonate for $10 \mathrm{~min}$. The filtered supernatant was mixed with $20 \mathrm{~mL}$ of distilled water and $10 \mathrm{~mL}$ of chloroform, where chloroform was evaporated with a steam bath, and the weight of caffeine was recorded [16,17].

\subsection{Residence time optimization for fermentation (Oxidation)}

Two types of fermentation have been practiced in the tea industry of Bangladesh for the production of CTC black tea [18]. In this case study, samples had been collected from the method of floor fermentation. For the optimization of the quality parameters of CTC black tea, TF and TR ratio measurement was taken at $10 \mathrm{~min}$ interval starting from 10 to $40 \mathrm{~min}$ of fermentation residence time. After the $40^{\text {th }}$ min of observation, the time interval was down to $5 \mathrm{~min}$ to get accurate TF: TR ratio and apposite residence time.

\subsection{Estimation of theaflavin (TF), thearubigin (TR), High polymerized substance (HPS) and total liquor color (TLC)}

Both theaflavin and thearubigin were determined using the method described in these reports $[19,20]$ with some modifications. Two grams of sample was added to $100 \mathrm{~mL}$ water and went to the filtration after infusing over the boiling water bath for $10 \mathrm{~min}$. Solvent extraction of tea extract was carried out in separating funnels with adequate shaking at every stage, and contents of TF, TR, HPS and TLC were calculated from the absorbance values. Color index (CI) was derived using the formula, $\mathrm{CI}=(\mathrm{TF} * 100) /(\mathrm{TR}$ + HPS) $[16,21]$. 


\subsection{Statistical analysis}

All analyses were performed in triplicates, and the results were generated in this experiment were analyzed using SPSS Software Version 12. Analysis of variance (ANOVA) was done to measure the effect of treatments on proximate, phytochemicals, and quality parameters (TF: TR, HPS, TC, CI), and means were separated by the least significant difference (LSD) test at $\mathrm{P}<0.05$.

\section{Results and Discussion}

\subsection{Changes in phytochemicals at the different processing stages}

Physical withering is the first and important operation during processing, which is usually done with ambient air at a velocity of $45 \mathrm{cfm}$ for $14 \mathrm{~h}$ to reduce the water content to facilitate subsequent operation. In addition, withering changes the biochemical components in the first 6-10 $\mathrm{h}$ of operation [22]. Withering reduced the content of all phytochemicals and proximate compositions were measured in this experiment without caffeine content (Table 1). The major changes occurred in the leaf appearance, where the moisture content of leaf reduced from 82.50 to $70.21 \%$, and reducing sugar reduced from 30 to $20.46 \mathrm{ppm}$. Changes in carotenoids and organic acids were found due to the breakdown of proteins to amino acids and the breakdown of chlorophyll due to a decrease in moisture content [2]. Besides, withering influences the volatile components and increase caffeine and polyphenol oxidase [2]. In addition, there was some flavor development during withering because of the reduction of lipid component from 8.67 to $7.67 \%$ (Table 1), which converted into volatile compounds [22].

Table 1. Phytochemicals and proximate composition at different tea processing stages.

\begin{tabular}{lccccl}
\hline & $\begin{array}{l}\text { Fresh tea } \\
\text { leaves }\end{array}$ & $\begin{array}{l}\text { Withered } \\
\text { leaves }\end{array}$ & $\begin{array}{l}\text { CTC rolled } \\
\text { leaves }\end{array}$ & $\begin{array}{l}\text { Fermented } \\
\text { tea leaves }\end{array}$ & $\begin{array}{l}\text { Dried black } \\
\text { tea }\end{array}$ \\
\hline Chlorophyll-a (mg/g) & $02.55 \pm 0.01$ & $1.82 \pm 0.03$ & $01.30 \pm 0.02$ & $0.93 \pm 0.06$ & N/A \\
Chlorophyll-b (mg/g) & $01.72 \pm 0.07$ & $0.97 \pm 0.08$ & $0.64 \pm 0.01$ & $0.46 \pm 0.03$ & N/A \\
Carotenoids (mg/g) & $0.47 \pm 0.02$ & $0.38 \pm 0.04$ & $0.48 \pm 0.01$ & $0.57 \pm 0.03$ & N/A \\
Moisture content \% & $82.50 \pm 1.16$ & $70.21 \pm 0.41$ & $67.02 \pm 1.73$ & $60.90 \pm 0.34$ & $05.06 \pm 0.11$ \\
Reducing sugar (ppm) & $30.83 \pm 0.84$ & $20.46 \pm 0.68$ & $04.95 \pm 0.64$ & $06.66 \pm 0.79$ & $20.72 \pm 0.57$ \\
Lipid \% & $08.67 \pm 0.07$ & $07.67 \pm 0.08$ & $06.84 \pm 0.03$ & $05.30 \pm 0.05$ & $04.84 \pm 0.07$ \\
Polyphenol (ppm) & $44.66 \pm 0.47$ & $42.30 \pm 0.94$ & $30.73 \pm 0.12$ & $18.23 \pm 0.16$ & $13.59 \pm 0.27$ \\
Catechin (ppm) & $17.41 \pm 0.09$ & $16.88 \pm 0.27$ & $07.95 \pm 0.16$ & $03.98 \pm 0.66$ & $01.61 \pm 0.18$ \\
Caffeine \% & $03.07 \pm 0.02$ & $03.29 \pm 0.05$ & $02.93 \pm 0.04$ & $02.77 \pm 0.06$ & $02.35 \pm 0.04$ \\
\hline
\end{tabular}

$* \mathrm{~N} / \mathrm{A}=$ Not applicable

CTC that crush, tear, and curl the withered leaves to provide small size and granular shape of black tea also facilitate the fermentation. Unlike withering, all phytochemical contents were reduced, as summarized in Table 1. The major and drastic reduction occurred in the reducing sugar (from 20.46 to $04.95 \mathrm{ppm}$ ), a polyphenol (from 42.30 to 
$30.73 \mathrm{ppm}$ ), and catechin (from 16.88 to $07.95 \mathrm{ppm}$ ) content after CTC processing (Table 1). During CTC processing, the withered leaves were crushed and tore; therefore, the cell contents of the bruised material have become more exposed by mixing and aeration. Subsequently, enzymatic action started in the presence of atmospheric oxygen. Thus, oxidation of the catechin and polyphenol initiated in this stage, which eventually decreased their contents [3,4,22,23].

Fermentation (oxidation) is the most significant step during tea processing in terms of biochemical changes, and the main liquoring characters of made tea are developed during this process $[15,18]$. Like CTC operation, all the phytochemical contents reduced during fermentation, and major changes occurred in polyphenol and catechin (Table 1). Total polyphenol content was decreased to $18.23 \mathrm{ppm}$, which was found 44.66 and $30.73 \mathrm{ppm}$ in fresh tea leaves and CTC rolled leaves, respectively (Table 1). In addition, the catechin content was decreased from 17.41 to $3.98 \mathrm{ppm}$ after fermentation. During CTC, the disruption and macerations of the intercellular components exposed polyphenol and catechin present in the cell vacuole and facilitated oxidation [24-27]. Thus, the oxidation (fermentation) of polyphenol and catechin by the polyphenol oxidase and peroxidase enzyme mainly occurred during fermentation to develop theaflavins (TF) and thearubigins (TR). The oxidization of catechins forms orthoquinones to make theaflavins (TFs) and oxidation of gallic acid form epitheaflavic acids, which condense with TFs to produce TRs [5,6,27].

Drying is a very important process that seizes the enzyme activity and reduces the moisture content of the final product. The increased temperature and reduction of moisture content in the tea leaves have the effect of denaturing and inactivating the enzymes to preserve the black tea quality $[28,29]$. Moisture content reduced to $5.06 \%$ in dried leaves from $60.90 \%$ in fermented leaves (Table 1). A similar observation was reported in respect of reducing the moisture in black tea [27]. Lipid and caffeine are the least changed components through the processing, while some lipids were oxidized into brown pigment products due to higher temperatures. Higher drying temperature negatively affects the tea polyphenol content and catechin content $[12,19,30]$. Still, the polyphenol content and caffeine content are similar or even better than that of some black tea available in the market of Bangladesh [31,32]. The total lipid content of black tea varied from 4 to $9 \%$, and the conversion of lipids to volatile compounds during the processing of tea is associated with the development of flavor as some of the lipid contents convert into aroma compounds [28].

\subsection{Optimum fermentation time}

TFs and TRs are the most influential compounds to tea quality, TFs are responsible for briskness, brightness, and quality of the liquor [32], whereas TRs are responsible for color, body, and taste. The TF and TR ratio should be 1:10 to 1:12 to have the excellent quality of black tea $[3,5,7,16]$. Fermentation time or fermentation residence time is one of the major factors in the maintenance of the TF and TR ratio. In this study, 10 min of fermentation process gave the TF: TR ratio of approximately 1:2.11 (Fig. 1). With less 
time of fermentation, the rate of TFs formation was low, and this slow rate was due to the low activity of polyphenol oxidase enzyme [4-6]. With the increasing fermentation time, TF: TR ratio increased, and the ratio becomes 1:8.39 during $50 \mathrm{~min}$ of residence (Fig. 1).

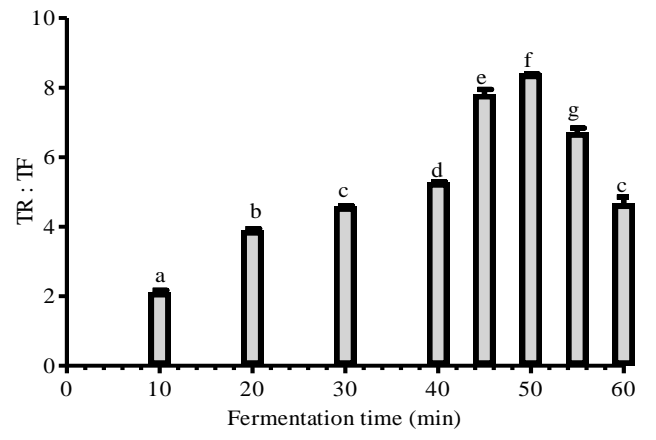

Fig. 1. Theaflavin and thearubigin ratio (TR:TF) at different fermentation time.

With increasing time, enzyme activity increases, which converts more TF into TR. Tea catechins are oxidized to form TFs, then TFs oxidize gallic acid from epitheaflavic acids, which later condensed with TFs to form TRs [5]. Further increase in fermentation time reduces TF: TR due to over oxidation of TFs. The researcher of Kenya showed that the maximum level of TFs was reached after approximately 90 min of fermentation [33], whereas Turkish black tea reached their maximum level of TFs after approximately 80 min of fermentation [34]. These differences in the optimum fermentation time are most probably due to the changes in environmental conditions based on the region of cultivation system as well as polyphenol oxidase (PPO) activity of the tea itself. Therefore, it was shown that 50 min of fermentation time gives the highest TF: TR ratio of approximately 1:9, and it turns into $\sim 1: 10$ after drying, which is desirable for a better quality of tea.

\subsection{Quality parameters of made tea (after drying) at optimum fermentation time}

The cup quality was assessed with the optimally fermented (50 min fermentation) black tea after drying on the basis of quality parameters (Table 2). The TF: TR was found 1:10, which was desired to prepare the best quality of made tea. The quality characteristics assessed in this study were also comparable to or better than black tea available in the market of Bangladesh. There is a study that measured the qualitative characteristics of some black tea in Bangladesh and found that the highest total liquor color (TLC) was 3.21 and highly polymerized substances (HPS) was $6.25 \%$ [35] which results lower than the values we found in this study. Another research study who processed tea according to the conventional fermentation method found that TLC and Color index were $4.25 \%$ and 3.50 , respectively [16], whereas this study found TLC was $4.75 \%$, and the color index was 4.31 . 
Table 2. Quality parameters of made tea.

\begin{tabular}{ll}
\hline TF $\%$ & $0.60 \pm 0.05$ \\
TR $\%$ & $5.82 \pm 0.07$ \\
TF: TR & $1: 9.95 \pm 0.35$ \\
High polymerized substance (HPS) $\%$ & $8.01 \pm 0.22$ \\
Total liquor color (TLC) $\%$ & $4.75 \pm 0.15$ \\
Color index (CI) & $4.31 \pm 0.21$ \\
\hline
\end{tabular}

\section{Conclusion}

The significant biochemical changes started in the stage of the withering and CTC process during black tea manufacture, and major changes took place during fermentation (oxidation). Polyphenol and catechin are two major compounds that decreased significant amounts by CTC and fermentation to produce theaflavins (TFs), thearubigins (TRs), high polymerized substance (HPS), total liquor color (TLC) and color index (CI). The ratio of TFs and TRs depends on the duration of fermentation. TFs and TRs ratio increased with increasing fermentation time, and $50 \mathrm{~min}$ of fermentation gave the highest TFs and TRs ratio, which also, in turn, came out as the highest TFs and TRs ratio of approximately 1:10 in the final product or black tea. The final product made from this fermentation gave comparatively better cup quality than that of the available tea in the market. As environmental temperature and humidity changes with seasonal change, further study on fermentation time during different tea processing season is recommended.

\section{Acknowledgments}

The author expresses his sincere thanks to the Director, SUST Research Centre, Shahjalal University of Science and Technology, Sylhet, Bangladesh, for the financial support to conduct this research project.

\section{References}

1. World Tea Production and Trade Current and Future Development (Trade and Markets Division, Food and Agriculture Organization of the United Nations (FAO), Rome, Italy, 2015). http://www.fao.org/publications/card/en/c/f7105b90-cf6d-4abc-84ec-7a7bd6b12da9

2. S. Deb and K. R. J. Pou, J. Biosystems Eng. 41, 365 (2016). https://doi.org/10.5307/JBE.2016.41.4.365

3. D. L. Sana, Tea Science (Ashrafia Boi Ghar, Dhaka, 1989) pp. 248-266.

4. P. M. Kumar, Ann. Rep. UPASI Tea Res. Foundation 84, 44 (2010).

5. Y. S. Chen, B. L. Liu, and Y. N. Chang, J. Biosci. Bioeng. 109, 557 (2010). https://doi.org/10.1016/j.jbiosc.2009.11.004

6. K. R. J. Pou, J. Biosystems Eng. 41, 85 (2016).https://doi.org/10.5307/JBE.2016.41.2.085

7. M. R. Karim, M. A. Choudhury, A. K. M. G. Kibria, and M. H. Rahman, Tea J. Bangladesh 36, 38 (2000).

8. N. Bhattacharyya, B. S. Seth, B.Tudu, P. Tamuly, A. Jana, D. Ghosh, R. Bandyopadhyay, and M. Bhuyan. J. Food Eng. 80, 1146 (2007). https://doi.org/10.1016/j.jfoodeng.2006.09.006

9. D. J. Milon, Quality Control in Food Industry, $4^{\text {th }}$ Edition (S. Herschdoctor Academic Press, London, England) 
10. M. R. Ullah, Alternative Test for Assessment of Fermentation - Proceed. of the 29th Tocklai Conference (TC'77) (Assam, India, 1977) pp. 75-77.

11. Approved Methods of the American Association of Cereal Chemists. $10^{\text {th }}$ Edition (American Association of Cereal Chemists, St. Paul, MN, 2000).

12. R. Ravichandran and R. Parthiban. Food Chem. 68, 7 (2000). https://doi.org/10.1016/S0308-8146(99)00143-0

13. J. E. Hedge and B. T. Hofreiter, Carbohydrate Chemistry (Academic Press, New York, 1962).

14. M. N. D. Choudhary and M. R. Goswami, Two Bud 30, 59 (1983)

15. A. R. Wellburn, J. Plant Physiol. 144, 307 (1994). https://doi.org/10.1016/S0176-1617(11)81192-2

16. M. S. A. Mamun, M. M. Hoque, M. Ahmed, and M. Yasin, Asian J. Plant Sci. 15, 16 (2016). https://doi.org/10.3923/ajps.2016.16.25

17. K. R. J.Pou, J. Biosystems Eng. 41, 85 (2016).http://dx.doi.org/10.5307/JBE.2016.41.2.085

18. M. A. Choudhury and M. N. Clifford, Tea J. Bangladesh 28, 30 (1992).

19. E. A. H. Roberts and R. F. Smith, Analyst. 86, 94 (1961). https://doi.org/10.1039/an9618600094

20. D. Baruah, L. P. Bhuyan, and M. Hazarika, Two Bud 59, 134 (2012).

21. S. N. S. Thanaraj and R. Seshadri, J. Sci. Food Agric. 51, 60 (1990). https://doi.org/10.1002/jsfa.2740510107

22. Y. Hara, S. J. Luo, R. L. Wickremasinghe, and T. Yamanishi, Food Rev. Int. 11, 371 (1995)

23. E. Sheibani1 , S. E. Duncan, D. D. Kuhn, A. M. Dietrich, J. J. Newkirk, and S. F. O'Keefe, Food Sci. Nutr. 4, 456 (2016). https://doi.org/10.1002/fsn3.307

24. T. Muthumani and R. S. Kumar, Food Chem. 101, 98 (2007) https://doi.org/10.1016/j.foodchem.2006.01.008

25. A. Robertson, in Tea Cultivation to Consumption - The chemistry and Biochemistry of Black Tea Production-the non-volatiles, ed. K.C. Willson et al. (Chapman \& Hall, London (1992) pp. 555-601. https://doi.org/10.1007/978-94-011-2326-6_17

26. N. Subramanian, P. Yenkatesh, S. Ganguli, and Y. P. Sinkar. J. Agric. Food Chem. 47, 2571 (1999). https://doi.org/10.1021/jf981042y

27. M. Rahman, I. A. Jahan, K. S. Ahmed, W. Zaman, I. Ahmad, and S. Ahmed, SUST J. Technol. 29, 52 (2019).

28. F. A. Ali, A. M. A. Badee, W. Z. A. Mikhail, and Meleka, M. G. B. Zagazig J. Agric. Res. 39, 263 (2012)

29. M. M. Molla, Tea J. of Bangladesh. 20, 31 (1984). https://doi.org/10.1002/jsfa.2740110308

30. E. A. H. Roberts and R. F. Smith, J. Sci. Food Agric. 11, 158 (1963).

31. G. M. R. Islam, G. Uddin, M. M. Rahman, and A. Yousuf, Mal. J. Nutr. 19, 143 (2013).

32. I. Ahmad, A. Z. M. S. Mazumder, F. B. Sumi, M, A. Hossain, and M. M. Hoque, J. App. Sci. Technol. 9, 107 (2013).

33. P. O. Owuor and M. Obanda, Food Sci. Technol. Int. Tokyo 4, 136 (1998). https://doi.org/10.3136/fsti9596t9798.4.136

34. M. Tufekci and S. Guner, Food Chem. 60, 56 (1997). https://doi.org/10.1016/S0308-8146(96)00302-0

35. K. M. M. Alam,R. Ahmed, C. Rashid, M. S. Uddin, and M. A. M. Chowdhury. Universal J. Plant Sci. 3, 43 (2015). 